Article

\title{
Cyclodehydration of 1,4-butanediol over Zr-Al Catalysts: Effect of Reaction Medium
}

\author{
Kuo-Tseng Li * and Kuan-Wen Chen \\ Department of Chemical Engineering, Tunghai University, Taichung 40704, Taiwan \\ * Correspondence: ktli@thu.edu.tw
}

Received: 5 June 2019; Accepted: 25 June 2019; Published: 28 June 2019

check for updates

\begin{abstract}
The conversion of 1,4-butanediol (BDO) to tetrahydrofuran (THF) in aqueous phase is desirable because $\mathrm{BDO}$ production technology is shifting to bio-based aqueous fermentation routes. In this study, liquid-phase cyclodehydration of $\mathrm{BDO}$ to THF was studied in two reaction media (pure $\mathrm{BDO}$ and aqueous $\mathrm{BDO}$ feeds) at $200-240{ }^{\circ} \mathrm{C}$ using $\mathrm{ZrO}_{2}-\mathrm{Al}_{2} \mathrm{O}_{3}$ (ZA) mixed oxides, which were made with a co-precipitation method and were characterized with XRD, BET, SEM/EDX, pyridine and $\mathrm{n}$-butylamine adsorptions. The maximum acidity and the largest surface area occurred at $\mathrm{Zr} / \mathrm{Al}$ atomic ratios of 1/1 (ZA11) and 1/3 (ZA13), respectively. The reaction exhibited pseudo-first-order; aqueous $\mathrm{BDO}$ feed had much greater rate constant than pure BDO feed, ascribed to the acidic properties of adsorbed water molecules (coordinated to surface metal cations) for the former case. For pure BDO feed, linear relation was observed between rate constant and catalyst acidity, and ZA11 reached a THF yield of $90.1 \%$ at $240{ }^{\circ} \mathrm{C}$. With aqueous BDO feed, rate constant increased linearly with increasing surface area and ZA13 reached a THF yield of $97.1 \%$ at $220^{\circ} \mathrm{C}$. The change of optimum catalyst composition with reaction medium suggests that active sites for catalyzing BDO cyclodehydration changed with the reaction environment.
\end{abstract}

Keywords: tetrahydrofuran; 1,4-butanediol; Zr-Al mixed oxides; aqueous-phase cyclodehydration; coordinated water

\section{Introduction}

Tetrahydrofuran (abbreviated as THF) is an important fine chemical intermediate and a powerful organic solvent. Most THF production is used to make polytetramethylene glycerol (abbreviated as PTMG, also known as poly-THF), which is used in the production of urethane elastomers, polyurethane fibers (ether-based spandex), and copolyester-ether elastomers. The remaining THF production is used as a solvent for the manufacture of poly (vinyl chloride) cements and coating, precision magnetic tape, a reaction solvent in the production of pharmaceuticals, and other miscellaneous uses [1].

THF is typically produced by cyclodehydration of 1,4-butanediol (abbreviated as BDO, shown in Equation (1)), which includes the removal of a $\mathrm{OH}$ group from a BDO molecule and the removal of a proton from the same molecule [2].

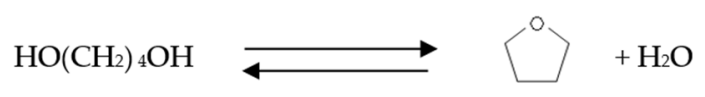

BDO dehydration is endothermic [2,3] and can be regarded as irreversible [4], especially at high reaction temperature (due to the fact that equilibrium constants for endothermic reactions increase with increasing temperature). It has been reported that $\mathrm{BDO}$ equilibrium conversion at $120^{\circ} \mathrm{C}$ was $99.75 \%$, and the backward reaction (the reaction between THF and water to form BDO) was not observed [4].

The commercial petroleum-derived BDO technologies include acetylene based process, butadiene-based process, maleic anhydride-based process, propylene-based process via allyl alcohol, 
and propylene oxide based process. In the commercial processes based on allyl alcohol and propylene oxide, 1,4-BDO is produced by hydrogenation of 4-hydroxyburaldehyde in aqueous solutions $[5,6]$. For economic reasons, it is better to convert 1,4-BDO to THF in aqueous solutions without water removal because the separation of $\mathrm{BDO}$ and water is costly.

$\mathrm{BDO}$ production technology is showing signs of transitioning from chemical synthesis routes to optimized bio-based fermentation routes. The emerging BDO technologies include esterification followed by hydrogenolysis of succinic acid (Myriant-Davy Process Technology), fermentation of sugar or biomass (Genomatica, San Diego, CA, USA), and hydrogenation of bio-succinic acid (produced from sugar fermentation, e.g., BioAmber, Montreal, Quebec, Canada) [7]. Most biological processes occur in aqueous solution, therefore, it is desirable to convert 1,4-BDO to THF in aqueous phase.

Reaction (1) can be catalyzed by liquid or solid acids such as strong mineral acids, heteropoly acids, silica gel, alumina, cation exchange resins, $\mathrm{ZrO}_{2}$, silica alumina and zeolites [8-10]. However, these catalysts have the following disadvantages: mineral acids may corrode equipment and pollute environments [11], heteropoly acids is costly, zeolites deactivate rapidly [12], cation exchange resins exhibited low THF production efficiencies $(\leqq 70 \%)$ under the rather low temperatures $\left(<120{ }^{\circ} \mathrm{C}\right)$ employed [4,13], vapor phase dehydration of $\mathrm{BDO}$ on $\mathrm{ZrO}_{2}$ exhibited low THF selectivity (less than $60 \%)[14]$.

Compressed water at a temperature above $200{ }^{\circ} \mathrm{C}$ possesses very interesting properties [15]. Hunter et al. studied the cyclodehydration of BDO to THF in high-temperature water $\left(200-350^{\circ} \mathrm{C}\right)$ without adding catalyst, THF yield obtained was less than $47 \%$ at $\mathrm{T} \leqq 250^{\circ} \mathrm{C}$ [16]. Yang et al. [12] studied cyclodehydration of 1,4-butanediol to THF in near-critical water $\left(260-340^{\circ} \mathrm{C}\right)$ with the addition of three metal sulfates $\left(\mathrm{Fe}_{2}\left(\mathrm{SO}_{4}\right)_{2}, \mathrm{ZnSO}_{4}\right.$, and $\left.\mathrm{NaHSO}_{4}\right)$. The maximum THF yield obtained was $59.85 \mathrm{wt} \%$ at $320^{\circ} \mathrm{C}, 120 \mathrm{~min}$ with the use of $\mathrm{Fe}_{2}\left(\mathrm{SO}_{4}\right)_{2}$. It is desirable to decrease the reaction temperature and to increase THF yield for BDO cyclodehydration in aqueous solution using heterogeneous catalysts.

Mixed metal oxides have a wide spectrum of industrial applications [17]. The insertion of foreign metal atoms into the inorganic network of metal oxides is usually used in practice to create active sites with different functionality [18], such as acidic [19-23] or redox functionality [24-31]. $\mathrm{ZrO}_{2}-\mathrm{Al}_{2} \mathrm{O}_{3}$ mixed oxides have been prepared using sol-gel method [32-35], electrohydrodynamic atomization [36], co-precipitation method [37,38], laser-splatting [33], plasma spraying [33] and melt extraction [35]. Dabbagh and Zamani used alumina-zirconia mixed oxides (prepared with a sol-gel method) for dehydration of 2-octanol and 1,2-diphenyl-2-propanol to alkenes [32]. $\mathrm{No} \mathrm{ZrO}_{2}-\mathrm{Al}_{2} \mathrm{O}_{3}$ mixed oxides have been used for catalyzing cyclodehydration of BDO to THF.

The major purpose of this work is to decrease the reaction temperature and to increase THF yield for aqueous-phase 1,4-BDO cyclodehydration to form THF by using $\mathrm{ZrO}_{2}-\mathrm{Al}_{2} \mathrm{O}_{3}$ mixed oxides. The maximum THF yield we obtained for aqueous phase BDO cyclodehydration was $97.1 \%$ at $220{ }^{\circ} \mathrm{C}$, which was much better than those reported before. Another purpose of this work is to study the effect of water solvent on the catalytic performances of these catalysts. We found that the optimum $\mathrm{Zr}-\mathrm{Al}$ catalyst composition changed with reaction medium, which was ascribed to the change of active sites for BDO cyclodehydration.

\section{Materials and Methods}

\subsection{Catalyst Preparation and Characterization}

$\mathrm{ZrO}_{2}-\mathrm{Al}_{2} \mathrm{O}_{3}$ mixed oxides with $\mathrm{Zr} / \mathrm{Al}$ atomic ratios of $1 / 3,1 / 1$ and $3 / 1$ were prepared by a co-precipitation method. Zirconium tetrachloride (ACROS, 98\% purity) and aluminum trichloride hexahydrate (SHOWA, 97\%) were dissolved in anhydrous ethanol (ECHO, $>99.5 \%$ purity). The solution was mixed with aqueous ammonia (SHOWA, 28\%). The gel solution was aged at room temperature for $2 \mathrm{~h}$ and then the precipitate was filtered and washed with de-ionized water until no chloride ion was left. The precipitate was dried at $110^{\circ} \mathrm{C}$ for $12 \mathrm{~h}$, and then heated to $500{ }^{\circ} \mathrm{C}$ at a rate of $1{ }^{\circ} \mathrm{C} / \mathrm{min}$ and kept at $500{ }^{\circ} \mathrm{C}$ in air for $4 \mathrm{~h}$. For comparisons, single oxides $\left(\mathrm{ZrO}_{2}\right.$ alone, 
$\mathrm{Al}_{2} \mathrm{O}_{3}$ alone) were also prepared using the same procedure mentioned above except no aluminum trichloride hexahydrate was added for preparing pure $\mathrm{ZrO}_{2}$, and no zirconium tetrachloride was added for preparing pure $\mathrm{Al}_{2} \mathrm{O}_{3}$.

The catalyst specific surface area was determined by nitrogen adsorption with a Micromeritics (Norcross, GA, USA) surface area analyzer (model ASAP 2020). Before nitrogen adsorption, samples were degassed at $150{ }^{\circ} \mathrm{C}$ in vacuum for $3 \mathrm{~h}$. Catalyst acidic properties were measured by n-butylamine adsorption. Samples were heated at $150^{\circ} \mathrm{C}$ for $12 \mathrm{~h}$ and were degassed in vacuum for $3 \mathrm{~h}$ before putting in a desiccator with saturated n-butylamine vapor at room temperature for $48 \mathrm{~h}$. The samples were then degassed in vacuum to remove physically adsorbed n-butylamine. Then a TG apparatus (TA Q50, New Castle, DE, USA) was used to measure the weight loss of the adsorbed sample at programmed temperature (with a heating rate of $20^{\circ} \mathrm{C} / \mathrm{min}$, started from $30^{\circ} \mathrm{C}$ and ended at $550{ }^{\circ} \mathrm{C}$ ). The presence of Lewis and Bronsted acid sites in the catalyst samples were determined through infrared spectroscopy using pyridine as a probe molecule. Before pyridine adsorption, the samples were heated at $400{ }^{\circ} \mathrm{C}$ for $2 \mathrm{~h}$ and then cooled to room temperature in a U-shaped tube. Evaporated pyrideine was carried to the samples with flowing nitrogen $(250 \mathrm{ml} / \mathrm{min})$ for $30 \mathrm{~min}$. The samples were then analyzed with a FTIR (Shimazu IR-Prestige-21, Kyoto, Japan). Catalyst crystal structure was examined by X-ray diffraction (XRD) crystallography on a Shimadzu XRD-6000 diffractometer with $\mathrm{Cu} K \alpha$ radiation. Quantitative analysis of the elements on the catalyst surface was performed using a field emission scanning electron microscope (JEOL JSM-7000F, Tokyo, Japan) equipped with an Energy Dispersive X-ray Spectrometer (abbreviated as EDS, OXFORD INCA ENERGY 400, Abingdon, Oxfordshire, England).

\subsection{Reaction Studies}

Cyclodehydration of BDO was carried out with a $300 \mathrm{ml}$ stirred reactor (supplied by Parr Instruments Co., Moline, IL, USA). Two types of feed were used: $56 \mathrm{~g}$ pure BDO (ACROS, Geel, Belgium; $>99 \%$ purity) and $2.4 \mathrm{~g}$ BDO in $50 \mathrm{ml}$ de-ionized water. The feed and $0.2 \mathrm{~g}$ or $0.4 \mathrm{~g}$ catalysts prepared above were mixed together and charged into the reactor. The agitator speed was set at $600 \mathrm{rpm}$, and the reaction mixture was then heated to the desired temperature. The total pressure in the autoclave increased continuously with the progress of reaction due to the conversion of high boiling point $\mathrm{BDO}$ (b.p. $=230^{\circ} \mathrm{C}$ ) to low boiling THF (b.p. $=66^{\circ} \mathrm{C}$ ). At the end of the reaction, the component compositions were determined with a Shimadzu (Kyoto, Japan) GC-2014 gas chromatography equipped with a 60 m Restek (Bellefonte, PA, USA) Stabilwax-DB capillary column. 1,4-butanediol conversion was defined as the percentage of 1,4-butanediol in the feed that had reacted. THF yield was defined as the moles of THF obtained per mole of 1,4-butanediol in the feed.

\section{Results and Discussion}

\subsection{BDO Cyclodehydration with Pure BDO Feed}

For pure $\mathrm{BDO}$ feed, the effect of catalyst composition (expressed as $\mathrm{Zr} /(\mathrm{Zr}+\mathrm{Al})$ molar ratio) on $\mathrm{BDO}$ conversion and THF yield is shown in Figure 1, using $0.2 \mathrm{~g} \mathrm{ZrO}_{2}-\mathrm{Al}_{2} \mathrm{O}_{3}$ catalysts at $230-240{ }^{\circ} \mathrm{C}$ and $3 \mathrm{~h}$ reaction time. The catalytic activity decreases in the following order: $\mathrm{Zr} / \mathrm{Al}=1 / 1$ (denoted as $\mathrm{ZA} 11)>\mathrm{Zr} / \mathrm{Al}=3 / 1($ denoted as $\mathrm{ZA} 31)>\mathrm{Zr} / \mathrm{Al}=1 / 3($ denoted as $\mathrm{ZA} 13)>\mathrm{Zr} / \mathrm{Al}=0 / 1$ (denoted as $\mathrm{ZA01})>\mathrm{Zr} / \mathrm{Al}=1 / 0$ (denoted as $\mathrm{ZA} 10$ ). That is, $\mathrm{ZrO}_{2}-\mathrm{Al}_{2} \mathrm{O}_{3}$ binary oxides have significantly better catalytic performances than component oxides and ZA11 catalyst has the highest activity. THF yield is sensitive to the change of reaction temperature, time and catalyst amount. For ZA11 catalyst, THF yield increased from $42.4 \%$ at $220^{\circ} \mathrm{C}$ to $70.7 \%$ at $240{ }^{\circ} \mathrm{C}$ (shown in Figure 1, using $0.2 \mathrm{~g}$ catalyst and $3 \mathrm{~h}$ reaction time), and reached $90.1 \%$ with $0.4 \mathrm{~g}$ catalyst and $9 \mathrm{~h}$ reaction time at $240{ }^{\circ} \mathrm{C}$. 


\subsection{BDO Cyclodehydration Using Aqueous BDO Feed}

For $\mathrm{BDO}$ cyclodehydration in aqueous solution, the variation of $\mathrm{BDO}$ conversion and THF yield with the change of $\mathrm{ZrO}_{2}-\mathrm{Al}_{2} \mathrm{O}_{3}$ catalyst composition is shown in Figure 2, using $0.2 \mathrm{~g}$ catalyst at $220^{\circ} \mathrm{C}$ and $3 \mathrm{~h}$ reaction time.

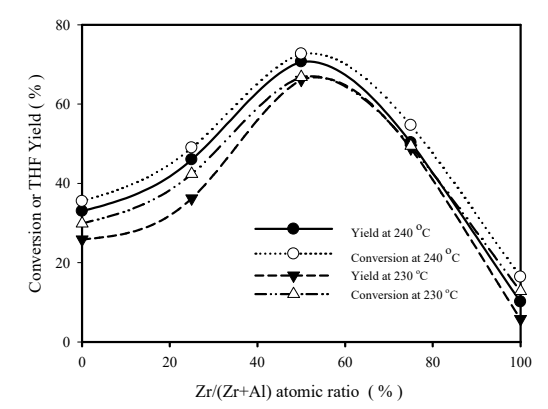

Figure 1. 1,4-butanediol (BDO) conversion and THF yield versus $\mathrm{Zr} /(\mathrm{Zr}+\mathrm{Al})$ molar ratio at $230-240{ }^{\circ} \mathrm{C}$ (pure BDO feed). Reaction conditions: $56 \mathrm{~g}$ pure BDO, $0.2 \mathrm{~g}$ catalyst, $\mathrm{t}=3 \mathrm{~h}$.

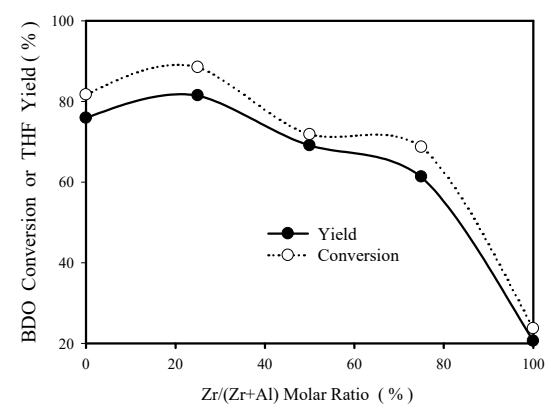

Figure 2. Effect of catalyst composition on THF yield and BDO conversion at $220^{\circ} \mathrm{C}$ (aqueous BDO feed). Reaction conditions: $2.4 \mathrm{~g}$ BDO in $50 \mathrm{ml}$ water, $0.2 \mathrm{~g}$ catalyst, $\mathrm{t}=3 \mathrm{~h}$.

In Figure 2, the activity order is ZA13 $>$ ZA10 $>$ ZA11 $>$ ZA31 $>$ ZA10. That is, ZA13 have the highest THF yield among these $\mathrm{Zr}$-Al oxides. It is interesting to note that the best catalyst changed from ZA11 to ZA13 when the feed was changed from pure BDO to aqueous BDO, which suggests that the active sites for $\mathrm{BDO}$ cyclodehydration might be different in these two reaction media. THF yield increased significantly with increasing catalyst amount. For ZA13 at $220^{\circ} \mathrm{C}$ and $3 \mathrm{~h}$, THF yield increased from $81.5 \%$ to $91.3 \%$ when catalyst amount was increased from $0.2 \mathrm{~g}$ to $0.4 \mathrm{~g}$. At the absence of catalyst and under the same reaction temperature and reaction time, THF yield was only $12.2 \%$, as shown in Figure 3.

Figure 3 shows the effect of reaction temperature (in a temperature range of $200-230{ }^{\circ} \mathrm{C}$ ) on ZA13 catalyst performances at $3 \mathrm{~h}$ in aqueous solution. Blank run (without catalyst addition) results are also shown in Figure 3 for comparisons. These results indicate that BDO conversion and THF yield increase rapidly with increasing reaction temperature. In the absence of catalyst, THF yields at $3 \mathrm{~h}$ are $3.7 \%, 12.2 \%$, and $16.3 \%$ at 210,220 , and $230{ }^{\circ} \mathrm{C}$, respectively. In the presence of $0.2 \mathrm{~g}$ ZA13 catalyst, the respective THF yields at $3 \mathrm{~h}$ are $67.8 \%, 81.5 \%$, and $88.3 \%$. That is, the addition of $0.2 \mathrm{~g}$ ZA13 catalyst greatly improved THF yield.

Figure 4 shows the effect of reaction time on THF yield in aqueous phase cyclodehydration for ZA13 at three temperatures $\left(200-220^{\circ} \mathrm{C}\right)$, indicating that the increase of reaction time significantly increases THF yield. At $200{ }^{\circ} \mathrm{C}$, THF yield increases from $28.8 \%$ at $1 \mathrm{~h}$ to $63.2 \%$ at $6 \mathrm{~h}$. At $220{ }^{\circ} \mathrm{C}$, THF yield increases from $60.5 \%$ at $1 \mathrm{~h}$ to $93.8 \%$ at $6 \mathrm{~h}$, and reached $97.1 \%$ (with a BDO conversion of $98.34 \%$ ) at $12 \mathrm{~h}$. This should be close to the equilibrium THF yield because of the high BDO conversion and long reaction time. 


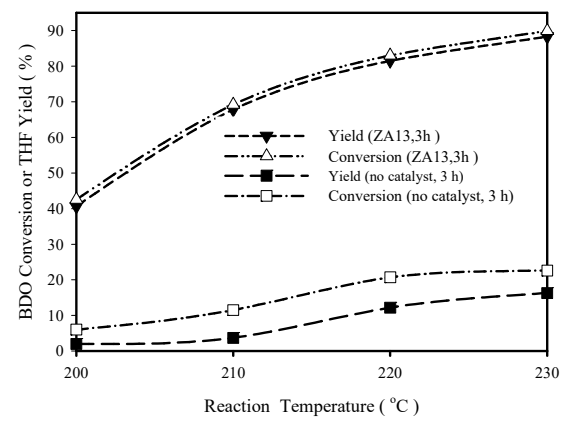

Figure 3. Influence of reaction temperature on tetrahydrofuran (THF) yield (aqueous BDO feed).Reaction conditions: $2.4 \mathrm{~g}$ BDO in $50 \mathrm{ml}$ water, $0.2 \mathrm{~g}$ catalyst, $\mathrm{t}=3 \mathrm{~h}$.

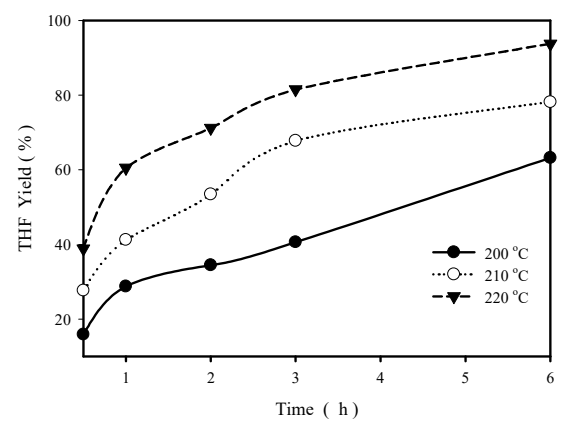

Figure 4. THF yield as a function of reaction time at three different temperatures $\left(200{ }^{\circ} \mathrm{C}, 210^{\circ} \mathrm{C}\right.$ and $220^{\circ} \mathrm{C}$ ). Reaction conditions: $2.4 \mathrm{~g}$ BDO in $50 \mathrm{~mL}$ water, $0.2 \mathrm{~g}$ catalyst.

Figure 5 compares the plots of $-\ln (1-X)$ versus reaction time for ZA13 (with aqueous BDO feed) and ZA11 (pure BDO feed), $\mathrm{X}$ is BDO conversion at $220^{\circ} \mathrm{C}$. This kind of plot is often used to test a pseudo-first-order rate law in a batch reactor [39]. Straight lines are obtained in Figure 5, therefore, the rate of BDO disappearance exhibits first-order with respect to BDO concentration. It is observed that the plots show the presence of intercepts (about 0.26) instead of showing zero, as predicted theoretically. The presence of such small intercepts is attributed to BDO conversion occurred during heating period (from room temperature to $220^{\circ} \mathrm{C}$ ). The rate constants, determined from slopes of the straight lines, are $0.605 / \mathrm{h}$ and $0.139 / \mathrm{h}$ for aqueous BDO feed (with ZA13 catalyst) and for pure BDO feed (with ZA11 catalyst), respectively. The former has much higher rate constant (4.35 times) than the latter, which are contrary to the results obtained by Vaidya et al. [13] and Baba et al. [9]. Vaidya et al. used a strong acid cation exchange resin to catalyze BDO cyclodehydration in a temperature range of $80-110^{\circ} \mathrm{C}$ and found that water inhibited the reaction, which was ascribed to the strong adsorption of water on active sites of resin. Baba and Ono used heteropoly acids to catalyze BDO cyclodehydration at $157^{\circ} \mathrm{C}$ and found that the reaction was much slower in water than in 1,4-dioxane, which was ascribed to proton hydrating of the heteropoly acids. The difference between our results and the previous results of Vaidya et al. and Baba et al. might be due to the difference of reaction temperature (water adsorption amount decreases with increasing temperature) and the difference of catalysts used.

For transitional metal oxides in aqueous solution, oxide surface is fully covered with adsorbed water and hydroxyl groups [40]. For molecularly adsorption, a water molecule is coordinated to the surface metal $\mathrm{M}(\mathrm{M}=\mathrm{Al}$ or $\mathrm{Zr}$ in this work) via partial transfer of charge from a water molecule to a metal cation (i.e., $\mathrm{M} \leftarrow \mathrm{OH}_{2}$ transfer), which weaken the $\mathrm{OH}$ bond and increase the positive charge on hydrogen. The coordinated water molecules are therefore tend to de-protonate according to Equation (2) [41].

$$
\left[\mathrm{M}-\mathrm{OH}_{2}\right]^{2+} \rightleftarrows[\mathrm{M}-\mathrm{OH}]^{(2-1)++\mathrm{Haq}^{+}} \rightleftarrows[\mathrm{M}-\mathrm{OH}]^{(2-2)+2+2 \mathrm{Haq}^{+}}
$$

where $\mathrm{z}=3$ and 4 for $\mathrm{Al}$ and $\mathrm{Zr}$, respectively. 
$\mathrm{Haq}^{+}\left(\right.$abbreviated as $\mathrm{H}^{+}$) produced from Equation (2) can catalyze BDO cyclodehydration to THF via one of the following mechanisms:

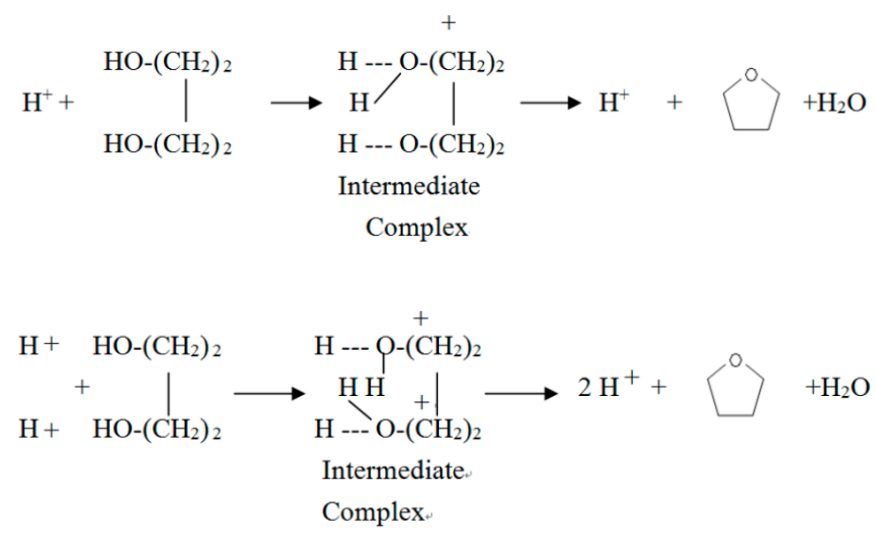

Equation (3) is a single site mechanism, which has been proposed for BDO cyclodehydration by heteropoly acids [9] and a zeolite (ZSM-5) [8]. Equation (4) is a dual site mechanism, which has been proposed before for $\mathrm{BDO}$ cyclodehydration on an acidic ion exchange resin [4]. In Equation (3), the transfer of a proton to oxygen of BDO gives an intermediate complex $\mathrm{H}_{2} \mathrm{OR}^{+} \mathrm{OH}\left(\mathrm{R}=\mathrm{C}_{4} \mathrm{H}_{8}\right)$, then a $\mathrm{H}_{2} \mathrm{O}$ molecule is lost from the ion, a THF molecule $\left(\mathrm{C}_{4} \mathrm{H}_{8} \mathrm{O}\right)$ is produced and one proton is regenerated. Based on Equation (3), Aghaziarati et al. [8] obtained the following rate equation for BDO (denoted as A) cyclodehydration:

$$
-\mathrm{r}_{\mathrm{A}}=\mathrm{kC}_{\mathrm{A}} /\left(1+\mathrm{K}_{\mathrm{A}} \mathrm{C}_{\mathrm{A}}\right)
$$

where $k$ is rate constant, $K_{A}$ is adsorption equilibrium constant of $A, C_{A}$ is concentration of $A$. They found that $\mathrm{K}_{\mathrm{A}}$ decreased rapidly with increasing reaction temperature with a heat of adsorption = $-33.28 \mathrm{~kJ} / \mathrm{mol}$. In the reaction condition we used ( $\left.\geqq 200^{\circ} \mathrm{C}\right), \mathrm{K}_{\mathrm{A}} \mathrm{C}_{\mathrm{A}}$ is much smaller than 1 because of high reaction temperature, Equation (5) becomes.

$$
-\mathrm{r}_{\mathrm{A}}=\mathrm{kC}_{\mathrm{A}}
$$

That is, reaction rate is 1st order with respect to BDO concentration, which is identical to the results we obtained in Figure 5.

\subsection{Catalyst Characterization Results}

Figure 6 shows the effect of catalyst composition on the amounts of acid sites (numerical values are shown on the left ordinate, determined with n-butylamine adsorption) and surface area (numerical values are shown on the right ordinate) for calcined $\mathrm{Zr}-\mathrm{Al}$ catalysts. Acidity decreases in the following order: ZA11 $>$ ZA13 $>$ ZA31 $>$ ZA01 $>$ ZA10, which is similar to the BDO cyclodehydration activity order obtained with pure BDO feed (ZA11 > ZA31 > ZA13 > ZA01 > ZA10, as shown in Figure 1).

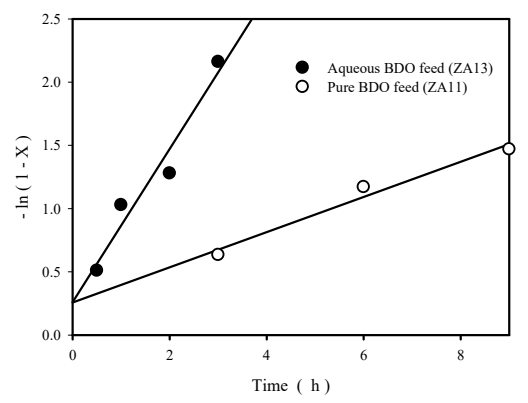

Figure 5. Plots of $-\ln (1-X)$ as a function of reaction time $\left(X\right.$ is BDO conversion) at $220^{\circ} \mathrm{C}$ for ZA13 catalyst (with aqueous BDO feed) and for ZA11 catalyst (with pure BDO feed). 


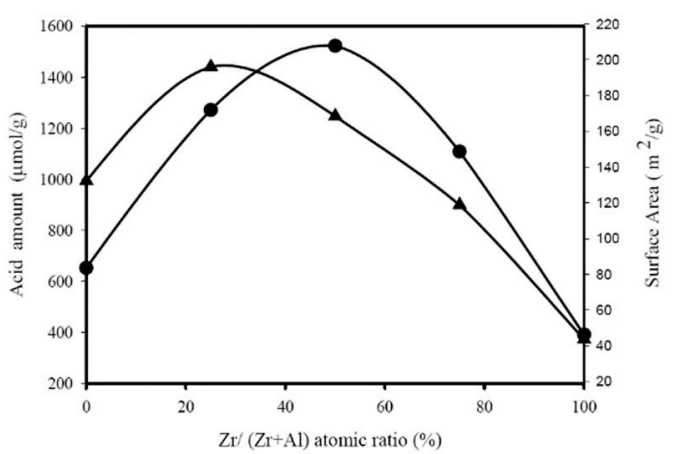

Figure 6. Influence of $\mathrm{Zr}$ content on the amounts of acid sites ( $\bullet$, refer to left ordinate) and surface area $\left(\boldsymbol{\Lambda}\right.$, refer to right ordinate) of $\mathrm{ZrO}_{2}-\mathrm{Al}_{2} \mathrm{O}_{3}$ oxides.

Figure 7 shows that a linear relationship is obtained by plotting first-order rate constants at $220{ }^{\circ} \mathrm{C}$ and $240{ }^{\circ} \mathrm{C}$ (obtained with pure BDO feed) as a function of catalyst acidity, suggesting that acid sites on $\mathrm{Zr}-\mathrm{Al}$ catalysts have similar activity for catalyzing BDO cyclodehydration to THF when the feed was pure BDO.

Figure 8 shows the adsorbed pyridine IR spectra of fresh (a) ZA13, (b) ZA11, and (c) ZA31 catalysts. The Bronsted and Lewis acid sites could be distinguished by the bands of chemisorbed pyridinium ion at IR wavenumber $\sim 1540 \mathrm{~cm}^{-1}$ and coordinative bonded pyridine at IR wavenumber $\sim 1440 \mathrm{~cm}^{-1}$, respectively. The band at IR wavenumber $\sim 1490 \mathrm{~cm}^{-1}$ is usually associated with pyridine adsorbed on both Bronsted and Lewis acid sites [42,43].

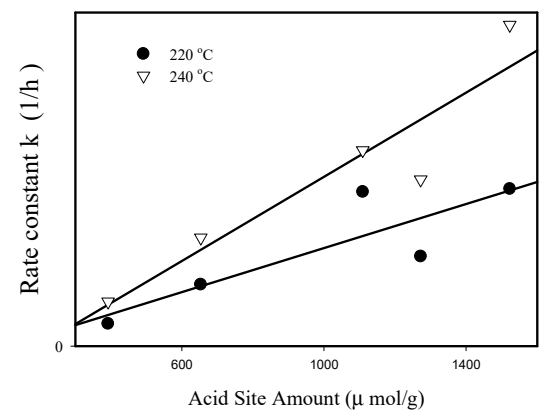

Figure 7. Correlation between first order rate constant $\mathrm{k}$ (with pure BDO feed, at $220{ }^{\circ} \mathrm{C}$ and $240{ }^{\circ} \mathrm{C}$ ) and acidity for $\mathrm{ZrO}_{2}-\mathrm{Al}_{2} \mathrm{O}_{3}$ oxides.

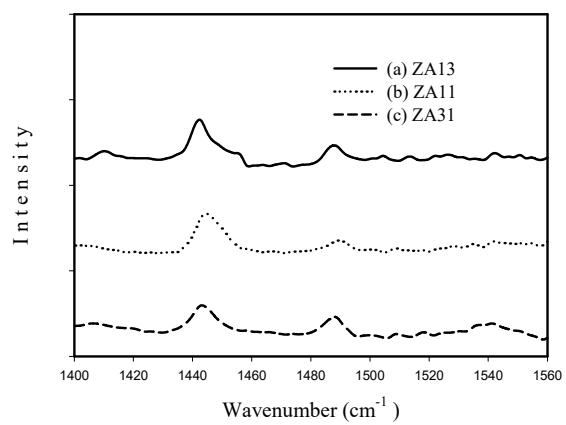

Figure 8. FT-IR spectra in 1400-1560 $\mathrm{cm}^{-1}$ spectral region for the fresh (a) ZA13, (b) ZA11, and (c) ZA31 catalysts.

Figure 8 indicates that the major acid sites existed in the calcined $\mathrm{Zr}-\mathrm{Al}$ mixed oxides are Lewis acid, because the peak at IR wavenumber $\sim 1440 \mathrm{~cm}^{-1}$ is strong (coordinative bonded pyridine due to pyridine on Lewis acid sites) and the peak at IR wavenumber $\sim 1540 \mathrm{~cm}^{-1}$ (chemisorbed pyridinium ion due to pyridine on Bronsted acid sites) is weak. 
The right ordinate of Figure 6 shows the variation of catalyst specific surface area as a function of $\mathrm{ZrO}_{2}-\mathrm{Al}_{2} \mathrm{O}_{3}$ catalyst composition, indicating that $\mathrm{ZA13}$ and $\mathrm{ZA11}$ mixed oxides have larger surface areas than pure oxides (ZA13 $>$ ZA11 $>$ ZA01 $>$ ZA31 $>$ ZA10). It is interesting to note that the $\mathrm{BDO}$ cyclodehydration activity order in aqueous solution (shown in Figure 2) is identical to the surface area order shown in Figure 6. A linear relationship is obtained by plotting the first-order rate constant (obtained with aqueous $\mathrm{BDO}$ feed) versus surface area for $\mathrm{Zr}$-Al catalysts, as shown in Figure 9, suggesting that the amount of $\mathrm{Haq}^{+}$produced from Equation (2) is proportional to the catalyst surface area.

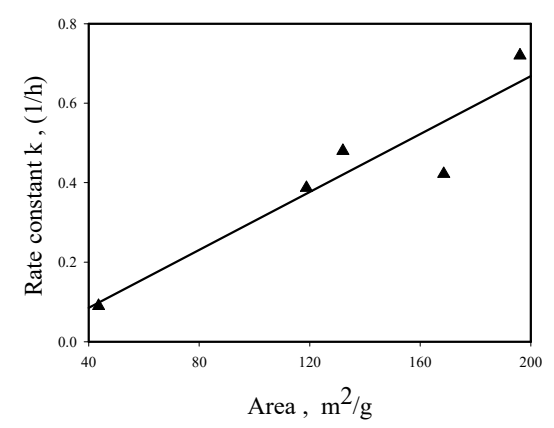

Figure 9. Correlation between first-order rate constant (in aqueous feed, at $220^{\circ} \mathrm{C}$ ) and surface area for $\mathrm{ZrO}_{2}-\mathrm{Al}_{2} \mathrm{O}_{3}$ oxides.

For $\mathrm{ZrO}_{2}-\mathrm{Al}_{2} \mathrm{O}_{3}$ oxides with aqueous $\mathrm{BDO}$ feed, areal reaction rates (calculated from Figures 2 and 6) are in the range of $0.22 \pm 0.3 \mathrm{mmol} \mathrm{THF} / \mathrm{m}^{2} . \mathrm{h}$ for all catalysts, which are not sensitive to the change of catalyst composition, suggesting that all $\mathrm{Haq}^{+}$produced from Equation (2) have similar activity for catalyzing BDO cyclodehydration to THF in aqueous solution.

Figure 10 presents X-ray diffraction (XRD) patterns of (A) ZA10, (B) ZA31, (C) ZA11, (D) ZA13, and (E) ZA01 catalysts. $\mathrm{ZrO}_{2}$ is crystalline with high intensity peaks (profile A), indicating that monoclinic phase predominates (peaks at $2 \theta=26^{\circ}, 29^{\circ}, 31^{\circ}, 40^{\circ}, 50^{\circ}, 53^{\circ}$ and $55^{\circ}$ ) with tetragonal phase present in small amount (peaks at $2 \theta=30^{\circ}, 35^{\circ}$ and $62^{\circ}$ ). It has been reported that the mixture of tetragonal and monoclinic phases has been formed after calcinations of originally amorphous hydrous zirconia at $450{ }^{\circ} \mathrm{C}$ [44]. ZA31 and ZA11 are amorphous solids and the broadened peak at $2 \theta \sim 30^{\circ}$ (profiles B and C) was considered as an appearance of amorphous zirconia [45]. The change from crystalline $\mathrm{ZrO}_{2}$ to amorphous ZA31 and ZA11 mixed oxides results in increasing surface area and acid site amount (shown in Figure 6), and increasing activity for BDO cyclodehydration to THF (shown in Figures 1 and 2). ZA13 and ZA01 have two peaks at $2 \theta \sim 46^{\circ}$ and $66.5^{\circ}$ (profiles D and E of Figure 10), which is the semicrystalline $\gamma$-alumina phase [46].

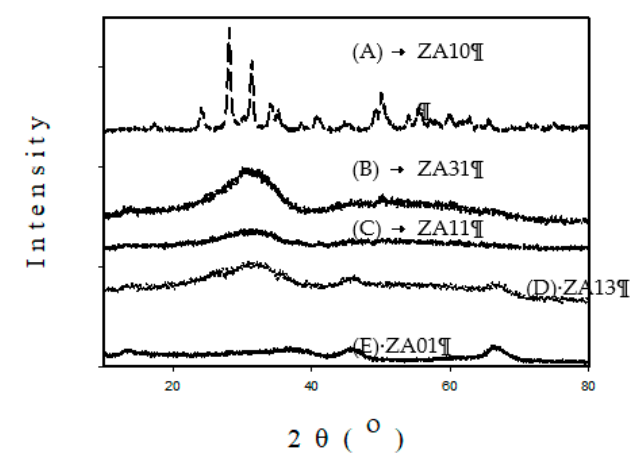

Figure 10. X-ray diffraction (XRD) patterns of (A) ZA10, (B) ZA31, (C) ZA11, (D) ZA13, and (E) ZA01 catalysts. 
EDS analyses indicated that surface $\mathrm{Zr} / \mathrm{Al}$ atomic ratios for ZA13, ZA11 and ZA31 were 1/3.7, $1 / 1.8$ and 3.3/1, respectively. The measured surface compositions were slightly different from precursor $\mathrm{Zr} / \mathrm{Al}$ atomic ratios $(1 / 3,1 / 1$, and $3 / 1)$ used for the preparation of these mixed oxides, which might be due to the solubility difference of the compounds involved in the catalyst precipitation process [40].

Figure 11 presents scanning electron microscopy (SEM) images of (a) ZA11 and (b) ZA13 with a magnification of 10,000 , indicating that ZA13 particle size is in the range of $2.5-5 \mu \mathrm{m}$, which is significantly larger than that of ZA11 particles $(<2.5 \mu \mathrm{m})$. The particle size difference might be due to the fact that ZA13 is partly crystalline solid and ZA11 is amorphous solid, as shown in Figure 10.

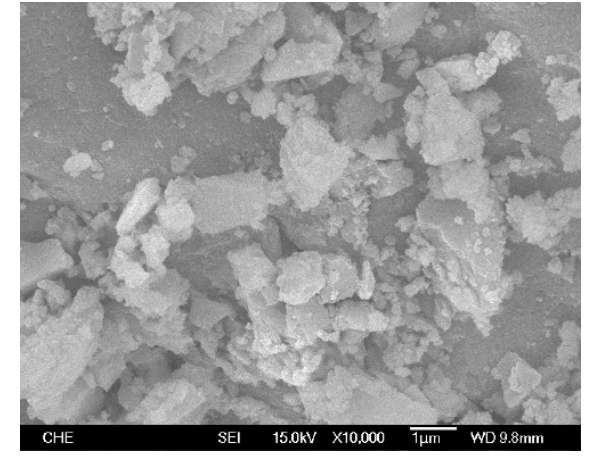

(a) ZA11

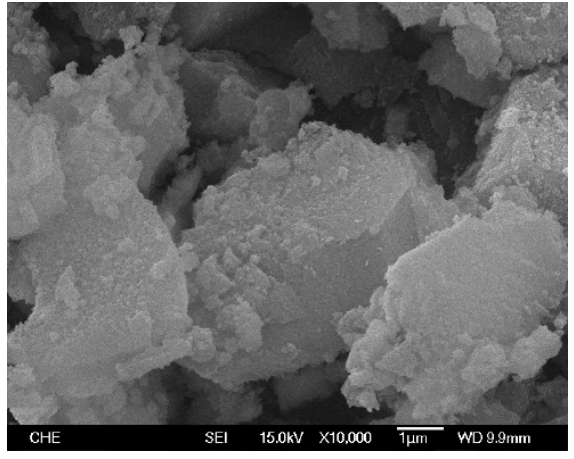

(b) ZA13

Figure 11. Scanning electron microscopy (SEM) images of (a) ZA11 and (b) ZA13 catalysts.

\section{Conclusions}

$\mathrm{ZrO}_{2}-\mathrm{Al}_{2} \mathrm{O}_{3}$ (ZA) mixed oxides with different atomic ratios were prepared with a co-precipitation method. These catalysts were used to catalyze the 1,4-butanediol (BDO) cyclodehydration to produce tetrahydrofuran (THF) with pure BDO feed and with aqueous BDO feed. When the feed was pure BDO, a linear relationship between THF yield and acidity was observed, ZA11 showed the best catalytic activity and reached a THF yield of $90.1 \%$ at $240{ }^{\circ} \mathrm{C}$. When the feed was aqueous BDO solution, a linear relationship between THF yield and surface area was observed, ZA13 exhibited the best catalytic activity and reached a THF yield of $97.1 \%$ at $220^{\circ} \mathrm{C}$. The pseudo-first-order rate constant obtained with aqueous BDO feed was much greater than that obtained with pure BDO feed, which was ascribed to the protons produced from the coordinated water molecules on the $\mathrm{Zr}-\mathrm{Al}$ catalyst surface in aqueous solution. ZA11 and ZA13 mixed oxides can reduce commercial THF production cost because they exhibited significant better THF yield than single oxide catalysts under identical reaction conditions.

Author Contributions: Conceptualization, K.-T.L.; methodology, K.-T.L. and K.-W.C.; investigation, K.-T.L. and K.-W.C.; resources, K.-T.L.; data curation, K.-W.C.; writing-original draft preparation, K.-T.L.; writing-review and editing, K.-T.L.; visualization, K.-W.C.; supervision, K.-T.L.; project administration, K.-T.L.; funding acquisition, K.-T.L.

Funding: This research was funded by ROC National Science Council, grant number NSC 101-2221-E-029-025 and the APC was funded by Tunghai University.

Acknowledgments: Figures 8, 10 and 11 were obtained by Lung-Der Tsai and Chao-Hsun Wu.

Conflicts of Interest: The authors declare no conflict of interest.

\section{References}

1. Karas, L.; Piel, W.J. Ethers. In Encyclopedia of Chemical Technology; Seidel, A., Ed.; Wiley: New York, NY, USA, 2005; Volume 10, pp. 567-583.

2. Winfield, M.E. Catalytic dehydration and hydration. In Catalysis; Emmett, P.H., Ed.; Reinhold: New York, NY, USA, 1960; Volume VII, pp. 93-182.

3. Kraus, M.; Knozinger, H. Elimination and addition reactions. In Handbook of Heterogeneous Catalysis; Ertl, G., Knozinger, H., Schuth, F., Weitkamp, J., Eds.; Wiley-VCH: Weinheim, Germany, 2008; Volume 7, pp. 3592-3603. 
4. Limbeck, U.; Altwicker, C.; Kunz, U.; Hoffmann, U. Rate expression for THF synthesis on acidic ion exchange resin. Chem. Eng. Sci. 2001, 56, 2171-2178. [CrossRef]

5. Dubner, W.S.; Shum, W.P. Production of butanediol. U.S. Patent 6,969,780, 29 November 2005.

6. Chen, S.C.; Chu, C.C.; Lin, F.S.; Chou, J.Y.; Huang, C.C. Modified Raney nickel catalyst and a process for preparing diols by using the same. U.S. Patent 5,888,923, 30 March 1999.

7. Ingram, A.; Le, B. 1,4-butanediol/tetrahydrofuran 2012-3 Report, Nexant's Chemsystems Process Evaluation/ Research Planning (PERP) Program. April 2013. Available online: http://thinking.nexant.com/sites/default/ files/report/field_attachment_abstract/201304/2012_3_abs.pdf (accessed on 5 June 2019).

8. Aghaziarati, M.; Kazemeini, M.; Soltanieh, M.; Sahebdelfar, S. Evaluation of Zeolites in Production of Tetrahydrofuran from 1,4-Butanediol: Performance Tests and Kinetic Investigations. Ind. Eng. Chem. Res. 2007, 46, 726-733. [CrossRef]

9. Baba, T.; Ono, Y. Kinetic studies in liquid phase dehydration-cyclization of 1,4-butanediol to tetrahydrofuran with heteropoly acids. J. Mol. Catal. 1986, 37, 317-326. [CrossRef]

10. Murata, A.; Tsuchiya, S. Jpn. Tetrahydrofuran from 1,4-butanediol. JP 48,001,075, 13 January 1973.

11. Li, K.T.; Peng, Y.C. Methylation of n-butylamine over solid-acid catalysts. Appl. Catal. A. Gen. 1994, 109, 225-233. [CrossRef]

12. Yang, Y.; Dai, L.Y.; Wang, J.S.; Zhou, H.Y. Research on additives assisted catalytic cyclo-dehydration of 1,4-butanediol to tetrahydrofuran in near-critical water. Adv. Mater. Res. 2012, 550-553, 693-698. [CrossRef]

13. Vaidya, S.H.; Bhandari, V.M.; Chaudhari, R.V. Reaction kinetics studies on catalytic dehydration of 1,4-butanediol using cation exchange resin. Appl. Catal. A. Gen. 2003, 242, 321-328. [CrossRef]

14. Yamamoto, N.; Sato, S.; Takahashi, R.; Inui, K. Synthesis of homoallyl alcohol from 1,4-butanediol over $\mathrm{ZrO}_{2}$ catalyst. Catal. Commun. 2005, 6, 480-484. [CrossRef]

15. Kruse, A.; Dinjus, E. Hot compressed water as reaction medium and reactant. J. Supercrit. Fluids 2007, 39, 362-380. [CrossRef]

16. Hunter, S.E.; Ehrenberger, C.E.; Savage, P.E. Kinetics and mechanism of tetrahydrofuran synthesis via 1,4-butanediol dehydration in high-temperature water. J. Organ. Chem. 2006, 71, 6229-6239. [CrossRef]

17. Gawande, M.B.; Pandey, R.K.; Jayaram, R.V. Role of mixed metal oxides in catalysis science-versatile applications in organic synthesis. Catal. Sci. Technol. 2012, 2, 1113-1125. [CrossRef]

18. Vandau, M.L. Sol-Gel processes. In Handbook of Heterogeneous Catalysis; Ertl, G., Knozinger, H., Schuth, F., Weitkamp, J., Eds.; Wiley-VCH: Weinheim, Germany, 2008; Volume 1, pp. 134-135.

19. Li, K.T.; Wang, C.Y. Succinic acid esterification on mixed oxides with titanium. Chem. Eng. Commun. 2016, 203, 1641-1647. [CrossRef]

20. Li, K.T.; Wang, I.; Wu, J.C. Surface and catalytic properties of $\mathrm{TiO}_{2}-\mathrm{ZrO}_{2}$ mixed oxides. Catal. Surv. Asia 2012, 16, 240-248. [CrossRef]

21. Li, K.T.; Wang, C.K.; Wang, I.; Wang, C.M. Esterification of lactic acid over $\mathrm{TiO}_{2}-\mathrm{ZrO}_{2}$ catalysts. Appl. Catal. A Gen. 2011, 392, 180-183. [CrossRef]

22. Li, K.T.; Tsai, L.D.; Wu, C.H.; Wang, I. Lactic acid esterification on titana-silica binary oxides. Ind. Eng. Chem. Res. 2013, 52, 734-739.

23. Li, K.T.; Wang, C.K. Esterification of lactic acid over $\mathrm{TiO}_{2}-\mathrm{Al}_{2} \mathrm{O}_{3}$ catalysts. Appl. Catal. A Gen. 2012, 433, 275-279. [CrossRef]

24. Li, K.T.; Yen, C.S.; Shyu, N.S. Mixed-metal oxide catalysts containing iron for selective oxidation of hydrogen sulfide to sulfur. Appl. Catal. A Gen. 1997, 156, 117-130. [CrossRef]

25. Li, K.T.; Huang, M.Y.; Cheng, W.D. Vanadium-based mixed oxide catalysts for selective oxidation of hydrogen sulfide to sulfur. Ind. Eng. Chem. Res. 1996, 35, 621-626. [CrossRef]

26. Li, K.T.; Shyu, N.S. Catalytic oxidation of hydrogen sulfide to sulfur on vanadium antimonite. Ind. Eng. Chem. Res. 1997, 36, 1480-1484. [CrossRef]

27. Li, K.T.; Chi, Z.H. Selective oxidation of hydrogen sulfide on rare earth orthovanadates and magnesium vanadates. Appl. Catal. A Gen. 2001, 206, 197-203. [CrossRef]

28. Li, K.T.; Huang, C.H. Selective oxidation of hydrogen sulfide to sulfur over $\mathrm{LaVO}_{4}$ catalyst: Promotional effect of antimony oxide addition. Ind. Eng. Chem. Res. 2006, 45, 7096-7199. [CrossRef]

29. Li, K.T.; Wu, K.S. Selective oxidation of hydrogen sulfide to sulfur on vanadium-based catalysts containing iron and antimony. Ind. Eng. Chem. Res. 2001, 40, 1052-1057. [CrossRef] 
30. Li, K.T.; Chi, Z.H. Effect of antimony oxide on magnesium vanadates for the selective oxidation of hydrogen sulfide to sulfur. Appl. Catal. B 2001, 31, 173-182. [CrossRef]

31. Li, K.T.; Huang, C.H. Iron-molybdenum-oxide catalysts for selective oxidation of hydrogen sulfide to sulfur. Canad. J. Chem. Eng. 1999, 77, 1141-1145. [CrossRef]

32. Dabbagh, H.A.; Zamani, M. Catalytic conversion of alcohols over alumina-zirconia mixed oxides: Reactivity and selectivity. Appl. Catal. A Gen. 2011, 404, 141-148. [CrossRef]

33. Kalonji, G.; McKittrick, J.; Hobbs, L.W. Applications of rapid solidification theory and practice to alumina-zirconia ceramics. In Advances in Ceramics; Claussen, N., Ruhle, M., Heuer, A.H., Eds.; American Ceramic Society: Columbus, OH, USA, 1983; Volume 17, pp. 816-825.

34. Jayaram, V.; Whitney, T.; Levi, C.G.; Mehrabian, R. Characterization of $\mathrm{Al}_{2} \mathrm{O}_{3}-\mathrm{ZrO}_{2}$ powders produced by electrohydrodynamic atomization. Mater. Sci. Eng. A 1990, 124, 65-81. [CrossRef]

35. McKittrick, J.; Kalonji, G.; Ando, T. Crystallization of a rapidly solidified $\mathrm{Al}_{2} \mathrm{O}_{3}-\mathrm{ZrO}_{2}$ eutectic glass. J. Non-Cryst. Sol. 1987, 94, 163-174. [CrossRef]

36. Soisuwan, S.; Panpranot, J.; Trimm, D.L.; Praserthdam, P. A study of alumina-zirconia mixed oxides prepared by the modified Pechini method as Co catalyst supports in CO hydrogenation. Appl. Catal. A Gen. 2006, 303, 268-272. [CrossRef]

37. Shibata, K.; Kiyoura, T.; Kitagawa, J.; Sumiyoshi, T.; Tanabe, K. Acidic properties of Binary Metal Oxides. Bull. Chem. Soc. Jpn. 1973, 46, 2985-2988. [CrossRef]

38. Li, G.; Li, W.; Zhang, M.; Tao, K. Characterization and catalytic application of homogeneous nano-composite oxides $\mathrm{ZrO}_{2}-\mathrm{Al}_{2} \mathrm{O}_{3}$. Catal. Today 2004, 93-95, 595-601. [CrossRef]

39. Fogler, H.S. Elements of Chemical Reaction Engineering, 4th ed.; Prentice Hall: Upper Saddle River, NJ, USA, 2006; pp. 267-268.

40. Kung, H.H. Transition Metal Oxides, Surface Chemistry and Catalysis; Elesvier: Amsterdam, The Netherlands, 1989; pp. 57-133.

41. Jolivet, J.P. Metal Oxide Chemistry and Synthesis: From Solution to Solid State; Wiley-VCH: Weinheim, Germany, 2003.

42. Hughes, T.R.; White, H.M. A study of the surface structure of decationized Y zeolite by quantitative infrared spectroscopy. J. Phys. Chem. 1967, 71, 2192-2201. [CrossRef]

43. Parry, E.P. An infrared study of pyridine adsorbed on acidic solids. Characterization of surface acidity. J. Catal. 1963, 2, 371-379. [CrossRef]

44. Kaluza, L.; Zdrazil, M. Preparation of zirconia-supported hydrodesulphurization catalysts by water-assisted spreading. Appl. Catal. A Gen. 2007, 329, 58-67. [CrossRef]

45. Damyanova, S.; Grange, P.; Delmon, B. Surface Characterization of Zirconia-Coated Alumina and Silica Carriers. J. Catal. 1997, 168, 421-430. [CrossRef]

46. Yang, X.; Sun, Z.; Wang, D.; Forsling, W. Surface acid-base properties and hydration/dehydration mechanisms of aluminum (hydr) oxides. J. Colloid Interface Sci. 2007, 308, 395-404. [CrossRef] [PubMed] 